\section{HISTOPATHOLOGICAL DIFFERENCES BETWEEN GENDERS IN PATIENTS WITH ORAL SQUAMOUS CELL CARCINOMA}

\author{
Fábio Muradás Girardi ${ }^{1}$, Giulia Rubin Fuga², Tássia Callai², \\ Marina Fernandes Bianchi²
}

\begin{abstract}
Introduction: Oral cancer ranks fifth among the most frequent malignant tumors in men in Brazil. The incidence of this tumor among women has grown. It is still controversial whether gender can influence the outcome or the prognostic features of the disease.

Objectives: To compare the histopathological features of oral squamous cell carcinomas between genders among patients undergoing surgical treatment in an oncological hospital of southern Brazil.
\end{abstract}

Methods: Between 2007 and 2011, 404 patients underwent resection of malignant tumors of the oral cavity in the head and neck department of this institution. A subgroup of 209 previously untreated oral cavity squamous cell carcinoma cases was selected for comparative analysis.

Results: In total, 68 participants were women and 141 were men. The tongue was the most common subsite in both genders. Men presented lower mean age and women presented tumors with smaller depth of invasion. Although among women it was observed a trend towards tumors with less aggressive characteristics, no other variable showed statistically significance.

Conclusion: Women with oral tumors tend to present more superficial primary tumors and at a later age.

Keywords: Oral neoplasms; carcinoma; squamous cell; prognosis

According to INCA estimates for the biennium 2016-2017', oral cavity cancer represents around $3.6 \%$ of incident malignancies in Brazil. Despite its low representativeness, the incidence and mortality from oral cavity cancer has been growing over the years in Brazil, differently from what has been seen in developed countries ${ }^{2}$. Nowadays, this cancer ranks fifth among the most common malignant tumors in men in Brazil, reaching the fourth position in southeast Brazil1. The squamous cell carcinoma (SCC) remains the most common malignancy of the oral cavity. Alcohol intake and smoking remain the main risk factors for the disease in Brazil| ${ }^{1}$. Apparently, the disparity in the reduction of alcohol and tobacco abuse among men and women seems to explain the increased incidence and mortality observed among female in some studies ${ }^{3}$, leading to a gradual reduction in the men:women ratio ${ }^{1,4}$. Although not included among the most incident malignancies of women in Brazil, about $28 \%$ of the new oral cavity cancers affect females in this country ${ }^{5}$.

Although current literature still lacks a consensus, there is a trend towards a better prognosis among women with oral cavity cancer ${ }^{1-4,6}$. Prognostic variations observed between genders might be explained by clinical and pathological differences between men and women. This study aims to evaluate the histopathological features at initial presentation by analyzing a historical series of patients surgically treated for oral cavity squamous cell carcinoma in an oncological hospital of southern Brazil.
Clin Biomed Res. 2017;37(3):147-150

1 Department of Head and Neck Surgery, Santa Rita Hospital, Santa Casa Hospital Complex. Porto Alegre, RS, Brazil.

2 School of Medicine, Universidade de Santa Cruz do Sul (UNISC). Santa Cruz do Sul, RS, Brazil.

Corresponding author: Fábio Muradás Girardi fabiomgirardi@gmail.com Department of Head and Neck Surgery, Santa Rita Hospital

R. Sarmento Leite, 187. 90050-170, Porto Alegre, RS, Brazil. 


\section{METHODS}

With the approval of the Research Ethics Committee of the author's Hospital, a retrospective analysis was performed involving all patients undergoing resection of malignant tumors of the oral cavity between the years 2007 and 2011 by the Head and Neck Surgery Department of this institution. During this period, 404 patients had their data reviewed. Patients treated without curative intention, cases previously treated for other head and neck malignant tumors, patients with lip tumors and those with histopathological results different from SCC were excluded from the analysis. Age and histopathological characteristics were compared between genders. In total, 209 patients were included in the final analysis.

It was considered an exiguous margin equal or inferior than $2 \mathrm{~mm}$. The seventh edition of UICC staging system was used to classify the clinical stage as either early (I-II) or advanced (III-IV). Histopathological grading of the surgery specimens was performed according to the World Health Organization (WHO) grading system. Lymph-node metastasis was classified as present or absent.

Descriptive analysis was used to summarize data. Kolmogorov-Smirnov test was performed for assessing normality of continuous variables. Continuous variables were expressed in mean and standard deviation or median, minimum and maximum value, as appropriate. Categorical variables were expressed in relative and absolute frequencies. Authors used student's $t$-test in the comparison of age means; Mann-Whitney test in the comparison of size and depth of invasion medians; and the non-parametric chi-square test in the comparison of categorical variables. Statistical analysis was performed through software SPSS version 15.0 (SPSS Inc., Chicago, IL). All tests considered a significance level of $5 \%$.

\section{RESULTS}

Tumors were distributed according to gender, histopathological characteristics and age, as demonstrated in Table 1. In total, there were 68 women

Table 1: Analysis of the clinical-pathological characteristics and survival according to gender among patients with oral squamous cell carcinomas.

\begin{tabular}{|c|c|c|c|c|c|c|c|c|}
\hline & & \multicolumn{2}{|c|}{ Women } & \multicolumn{2}{|c|}{ Men } & \multicolumn{2}{|c|}{ Total } & $p$ value \\
\hline \multirow{3}{*}{\multicolumn{2}{|c|}{ Age }} & \multicolumn{2}{|c|}{ Mean(SD) } & \multicolumn{2}{|c|}{ Mean(SD) } & \multicolumn{2}{|c|}{ Mean(SD) } & \\
\hline & & \multicolumn{2}{|c|}{$62.33(15.25)$} & \multicolumn{2}{|c|}{$58.31(13.17)$} & \multicolumn{2}{|c|}{$59.62(13.97)$} & 0.049 \\
\hline & & \multicolumn{2}{|c|}{ Median(min-max) } & \multicolumn{2}{|c|}{ Median(min-max) } & \multicolumn{2}{|c|}{ Median(min-max) } & \\
\hline \multirow{3}{*}{\multicolumn{2}{|c|}{$\begin{array}{l}\text { Size } \\
\text { Depth of invasion }\end{array}$}} & \multirow{2}{*}{\multicolumn{2}{|c|}{$\begin{array}{c}2.2(0.5-11) \\
0.6(0.1-4)\end{array}$}} & \multirow{2}{*}{\multicolumn{2}{|c|}{$\begin{array}{c}2.5(0.3-11.1) \\
1(0.1-4)\end{array}$}} & \multicolumn{2}{|c|}{$2.5(0.3-11.1)$} & 0.6448 \\
\hline & & & & & & 0.9 & $-4)$ & 0.0203 \\
\hline & & $N=68$ & $\%$ & $N=141$ & $\%$ & $N=209$ & $100 \%$ & \multirow{4}{*}{${ }^{*} 0.2393$} \\
\hline \multirow{7}{*}{ Differentiation } & WD & 24 & 35.2 & 39 & 27.6 & 63 & 30.1 & \\
\hline & MD & 25 & 36.7 & 72 & 51.0 & 97 & 46.4 & \\
\hline & PD & 9 & 13.2 & 17 & 12.0 & 26 & 12.4 & \\
\hline & Verrucous & 3 & 4.4 & 2 & 1.4 & 5 & 2.4 & --------- \\
\hline & In Situ & 2 & 2.9 & 0 & 0 & 2 & 1.0 & --------- \\
\hline & Microinvasive & 3 & 4.4 & 7 & 4.9 & 10 & 4.8 & --------- \\
\hline & Basaloid & 2 & 2.9 & 4 & 2.8 & 6 & 2.9 & --------- \\
\hline \multirow{3}{*}{$\begin{array}{l}\text { Growth } \\
\text { pattern }\end{array}$} & Expansive & 11 & 25.5 & 31 & 31.1 & 42 & 20.1 & \multirow{3}{*}{0.7790} \\
\hline & Infiltrative & 24 & 55.8 & 52 & 52.5 & 76 & 36.4 & \\
\hline & Mixed & 8 & 18.6 & 16 & 16.1 & 24 & 11.5 & \\
\hline \multicolumn{2}{|l|}{ Neural invasion } & 8 & 11.7 & 22 & 15.6 & 30 & 14.4 & 0.4584 \\
\hline \multicolumn{2}{|c|}{ Vascular invasion } & 1 & 1.4 & 5 & 3.5 & 6 & 2.9 & 0.3999 \\
\hline \multirow{2}{*}{$\mathrm{T}$} & Tis-T1-T2 & 51 & 75.0 & 89 & 64.9 & 140 & 67.0 & \multirow{2}{*}{0.1460} \\
\hline & T3-T4 & 17 & 25.0 & 48 & 35.0 & 65 & 31.1 & \\
\hline \multirow{2}{*}{$\mathrm{N}$} & No & 51 & 75.0 & 97 & 68.7 & 148 & 70.8 & \multirow{2}{*}{0.3552} \\
\hline & $\mathrm{N}+$ & 17 & 25.0 & 44 & 31.2 & 61 & 29.2 & \\
\hline \multirow{3}{*}{$\begin{array}{l}\text { Surgical } \\
\text { margins }\end{array}$} & Free & 27 & 39.7 & 46 & 32.6 & 73 & 34.9 & \multirow{3}{*}{0.4798} \\
\hline & Exiguous & 28 & 41.1 & 59 & 41.8 & 87 & 41.6 & \\
\hline & Compromised & 13 & 19.1 & 36 & 25.5 & 49 & 23.4 & \\
\hline
\end{tabular}

Variables are expressed in absolute $(\mathrm{N})$ and relative (\%) values, Mean (standard deviation) or Median (minimum-maximum), as appropriated; Age is expressed in years; T: T Staging; N: N Staging; WD: well differentiated; MD: moderately differentiated; PD: poorly differentiated; Size and Depth of invasion are expressed in centimeters; $p$ : significance level; * authors chose not to include other histological variants in statistical analysis, avoiding false-negative results attributable to low representativeness. 
$(32.5 \%)$ and 141 men $(67.4 \%)$, with a male:female ratio of $1: 2$. Tongue tumors were the most prevalent in both genders: 31(44.1\%) among women and $60(42.5 \%)$ among men. Men presented a lower mean age $(p=0.049)$. Women presented tumors with smaller depth of invasion $(p=0.0203)$. Neck dissection was performed in 43 women (63.2\%) and 110 men $(78.0 \%)$. It was not observed statistically significant differences in size $(p=0.6448)$, frequency of metastatic lymph nodes ( $p=0.3552)$, tumor differentiation ( $p=0.2393)$, growth pattern $(p=0.7790)$, surgical margin status ( $p=0.4798)$, and neural and vascular invasion rates ( $p=0.4584$ and $p=0.3999$, respectively) between genders.

\section{DISCUSSION}

There is evidence of an increasing incidence of oral malignant tumors among women over the last decades. In the 1950's, Pinsonneault and Gill ${ }^{7}$ observed that only $3.4 \%$ of oral cavity cancer cases in their series were represented by women, reaching $42.8 \%$ in the most recent series ${ }^{3,4}$. Since the 1950's researchers have already observed peculiarities in disease presentation when compared both genders. Despite the technical limitations of those studies, when affecting women, tumors used to present with a less infiltrative form, with lower response to radiotherapy and with lower prevalence of lymph node metastasis when compared to the male oral tumors ${ }^{7}$. During the following decades, few studies have added new information, most of them restricted to tumor subsite analysis, tobacco and alcohol consumption and age disparities.

With some variations in the literature, tongue and lips are the most involved subsites ${ }^{7}$, and SCC, the most common histological diagnosis. Some authors observed a higher prevalence of superior gingiva and hard palate tumors among women, and a higher proportion of tumors of floor of the mouth among men ${ }^{4}$.

Bross and Coombs ${ }^{8}$ observed that women exposed to alcohol and/or tobacco manifested the disease at an earlier age, suggesting that those habits could "hasten" the onset of the disease in females. Recent studies suggest that the longer life expectancy among females and perhaps the later exposure to risk factors can collaborate with differences in age at onset of the disease in some regions ${ }^{4}$.

Some authors observed a higher prevalence of early T stage among women ${ }^{6,9,10}$. Divergently, Kruse et al. found no statistically significant differences in $\mathrm{T}$ and $\mathrm{N}$ stages between genders ${ }^{4}$. Except for depth of invasion, no association between gender and other analyzed histopathological features were found in the author's study, despite the observed tendency of women presenting earlier stages. Even the rate of lymph node metastasis did not differ, suggesting that although women presented more superficial tumors, those findings were not associated with expressive lower regional metastasis rates. Other authors also observed similar results, ${ }^{6,10,11}$. Interestingly, Chen et al. also observed a higher prevalence of earlier stages among women, as well as an association between the presence of IL-6 tumor cytosolic, female gender and lymph node metastasis, demonstrating that other independent factors may also be involved in differences of metastasis risk between genders. It is possible that similar rates of lymph node metastasis may be correlated with similar disease survival curves when comparing men and women, since the $\mathrm{N}$ stage is one of the most important prognostic factors in oral cancer ${ }^{12,13}$.

\section{CONCLUSION}

Oral cavity carcinomas among women tend to present with more superficial tumors and at later ages. Nevertheless, there were no statistically difference in the prevalence of lymph node metastasis and other histopathological factors historically associated with the prognosis.

\section{Conflicts of interest}

The authors declare no conflicts of interest.

\section{REFERENCES}

1. Instituto Nacional do Câncer (INCA). Estimativa 2016, incidência de câncer no Brasil. Brasília: INCA; 2015. [cited 2016 Sept 19]. Available from: http:// www.inca.gov.br/estimativa/2016/ estimativa-2016-v11.pdf.

2. Girod A, Mosseri V, Jouffroy T, Point $\mathrm{D}$, Rodriguez J. Women and squamous cell carcinomas of the oral cavity and oropharynx: is there something new? J Oral Maxillofac Surg. 2009;67:1914-20.

3. Antunes JL, Toporcov TN, Biazevic MG, Boing AF, Bastos JL. Gender and racial inequalities in trends of oral cancer mortality in São Paulo, Brazil. Rev Saude Publica. 2013;47:470-8.

4. Kruse AL, Bredell M, Grätz KW. Oral cancer in men and women: are there differences? Oral Maxillofac Surg. 2011;15:51-5.

5. Arduino PG, Carrozzo M, Chiecchio A, Broccoletti R, Tirone F, Borra $\mathrm{E}$, et al. Clinical and histopathologic independent prognostic factors in oral squamous cell carcinoma: a retrospective study of 334 cases. J Oral Maxillofac Surg. 2008;66:1570-9. 
6. Honorato J, Rebelo MS, Dias FL, Camisasca DR, Faria PA, Azevedo e Silva G, et al. Gender differences in prognostic factors for oral cancer. Int J Oral Maxillofac Surg. 2015;44:1205-11.

7. Pinsonneault G, Gill G. Oral cancer in the female. Can Med Assoc J. 1950;62:148-50.

8. Bross ID, Coombs J. Early onset of oral cancer among women who drink and smoke. Oncology. 1976;33:136-9.

9. Carvalho MB, Lenzi J, Lehn CN, Fava AS, Amar A, Kanda AJ, et al.
Características clínico-epidemológicas do carcinoma epidermóide de cavidade oral no sexo feminino. Rev Assoc Med Bras. 2001;47:208-14.

10. Chen CJ, Sung WW, Lin YM, Chen $\mathrm{MK}$, Lee $\mathrm{CH}$, Lee H, et al. Gender difference in the prognostic role of interleukin 6 in oral squamous cell carcinoma. PLoS One. 2012;7:e50104.

11. Chen PH, Shieh TY, Ho PS, Tsai CC, Yang YH, Lin YC, et al. Prognostic factors associated with the survival of oral and pharyngeal carcinoma in Taiwan. BMC Cancer. 2007;7:101.

12. Thiagarajan S, Nair S, Nair D, Chaturvedi P, Kane SV, Agarwal JP, et al. Predictors of prognosis for squamous cell carcinoma of oral tongue. J Surg Oncol. 2014;109:63944.

13. Wang B, Zhang S, Yue K, Wang $X D$. The recurrence and survival of oral squamous cell carcinoma: a report of 275 cases. Chin J Cancer. 2013;32:614-8.

Received: Apr 28, 2017 Accepted: July 05, 2017 